\title{
Prevotella tannerae
}

National Cancer Institute

\section{Source}

National Cancer Institute. Prevotella tannerae. NCI Thesaurus. Code C86678.

A species of obligately anaerobic, Gram-negative, rod shaped bacteria assigned to the phylum Bacteroidetes. This species is nonmotile, non-spore forming, digests gelatin and milk, but not meat, hydrolyzes starch, but not esculin, does not reduce nitrate, produces hydrogen sulfide, produces acid from dextrin, fructose, glycogen, lactose, maltose, mannose, raffinose, starch, sucrose, and trehalose, and is resistant to tetracycline. P. tannerae was isolated from ging ival crevices where it is associated with endodontic infections. 